\title{
Correction to: Mismatch repair protein loss in breast cancer: clinicopathological associations in a large British Columbia cohort
}

\author{
Angela S. Cheng ${ }^{1} \cdot$ Samuel C. Y. Leung ${ }^{1} \cdot$ Dongxia Gao $^{1} \cdot$ Samantha Burugu ${ }^{1} \cdot$ Meenakshi Anurag $^{2} \cdot$ Matthew J. Ellis $^{2}$. \\ Torsten O. Nielsen ${ }^{1,3}$
}

Published online: 20 June 2020

(c) Springer Science+Business Media, LLC, part of Springer Nature 2020

\section{Correction to: \\ Breast Cancer Research and Treatment (2020) 179:3-10 https://doi.org/10.1007/s10549-019-05438-y}

Publisher's Note Springer Nature remains neutral with regard to jurisdictional claims in published maps and institutional affiliations.

In the original publication of the article, the funding statement was published incompletely. The corrected funding statement should read as below:

Funding This study was supported by the Canadian Cancer Society (Grant \#705463) to TON and BCRF (Award id: BCRF-19-042) to MJE.

The original article can be found online at https://doi.org/10.1007/ s10549-019-05438-y.

Torsten O. Nielsen

torsten@mail.ubc.ca

1 Genetic Pathology Evaluation Centre and University of British Columbia, Vancouver, BC, Canada

2 Baylor College of Medicine, Houston, TX, USA

3 Anatomical Pathology JPN1401 Vancouver Hospital, 855 West 12th Avenue, Vancouver, BC V5Z 1M9, Canada 